\title{
$\mathrm{RBS}$ 성능향상을 위한 연속 클럭 동기화 및 패킷 손실 보상 기법
}

트렁홉도", 박 근 원", 정 재 인 ${ }^{*}$, 유 명 식

\section{Continuous Clock Synchronization and Packet Loss Tolerance Scheme for Enhancing Performance of Reference Broadcast Synchronization}

\author{
Trong-Hop Do*, Konwon Park ${ }^{*}$, Jaein Jung*, Myungsik Yoo \\ 요 약
}

Reference Broadcast Synchronization (RBS)는 무선 센서 네트워크 동기화에 가장 널리 사용되는 프로토콜이다. 공통의 브로드케스트 채널이 존재할 경우 RBS는 상당히 높은 동기화 성능을 보인다. 그러나 RBS는 순간 클럭 동기화 (Instantaneous Clock Synchronization) 방식을 사용기 때문에 동기화 시간에 순간적인 시간 간격이 발생하 여 시스템의 불안정을 초래할 수 있다. 또한 RBS는 패킷 손실 보상 기능이 없어 무선 채널 환경이 열악한 경우 동기화 성능의 현저한 저하를 초래할 수 있다. 본 논문에서는 RBS의 순간 클럭 동기화에 의한 문제점과 패킷 손 실이 BRS 동기화에 미치는 영향에 대해서 분석한다. 이러한 문제점을 해결하기 위하여 RBS를 위한 연속 클럭 동 기화 방식과 패킷 손실 보상 방식을 제안하고, 모의실험을 통하여 제안 방식의 성능향상에 대해 검증하고자 한다.

Key Words : Packet loss, tolerance, reference broadcast, synchronization, wireless

\section{ABSTRACT}

Reference Broadcast Synchronization (RBS) is one of the most prominent synchronization protocols in wireless sensor nework. Given that the broadcasting medium is available, RBS can give very high accuracy of synchronization. However, RBS uses instantaneous synchronization and results in time discontinuity, which might cause serious faults in the distributed system. Also, RBS lacks packet loss tolerance, which brings about degraded performance in severe conditions of wireless channel. In this paper, the problem of time discontinuity in RBS is pointed out and the effect of packet loss on the performance of RBS is examined. Then, a continuous synchronization and a packet loss tolerance mechanism for RBS are proposed, and the result is verified through simulations.

※ 이 논문은 2012년도 정부(교육과학기술부)의 재원으로 한국연구재단의 지원을 받아 수행된 기초연구사업 연구임 (No. 2012R1A1A2 042995)

- First Author : School of Electronic Engineering, Soongsil University, dotronghop@gmail.com, 학생회원

- Corresponding Author : School of Electronic Engineering, Soongsil University, myoo@ssu.ac.kr, 정회원

* 숭실대학교

논문번호 : KICS2014-04-140, Received April 25, 2014; Revised May 23, 2014; Accepted May 23, 2014 


\section{I. 서 론}

무선 센서 네트워크(WSN)는 통신 및 데이터 처리 기능을 탑재한 센서들로 구성된 분산 네트워크이다. WSN는 무선의 장점으로 인하여 기존 유선 네트워크 비하여 구축이 용이하여 실시간 제어 시스템을 포함 한 다양한 산업분야의 통신 인프라로 사용되고 있 다. ${ }^{[1]} \mathrm{WSN}$ 에서의 분산 환경으로 인하여 각 센서 노 드에서 측정된 지역 시간 (Local Clock)은 분산 환경 의 다른 노드들에서 측정된 지역 시간들과 다르다는 문제가 있다. 이로 인하여 센서 노드들 간의 시간을 맞추기 위한 동기화 방식이 필요하다. ${ }^{[2]}$

$\mathrm{WSN}$ 의 시간 동기화를 위하여 많은 동기화 프로토 콜들이 제안되었다 ${ }^{[3-5]}$. 이들 동기화 프로토콜은 주로 메시지 교환에 의하여 동기화를 수행하기 때문에 무 선 채널의 채널 품질에 의한 패킷 손실률에 따라 그 성능이 저하되는 문제가 발생한다. 특히 동기화 성능 을 결정하는 요소로 전송시간 (Send Time), 채널 접 근시간 (Access Time), 전파시간 (Propagation Time), 수신시간 (Receive Time)에서 발생하는 시간 오차인 데, 이중 전송시간과 채널 접근시간은 동기화 오차를 발생시키는 주요 요소이다. ${ }^{[3]}$ Reference Broadcast Synchronization $(\mathrm{RBS})^{[4]}$ 프로토콜은 무선 방송 채널 의 잇점을 활용하여 전송시간과 채널 접근시간에서 발생하는 오류를 제거하여 동기화 정확도를 향상시켰 다. 그러나, $\mathrm{RBS}$ 에서 사용하는 순간 동기화 방식 (Instantaneous Synchronization Mechanism)은 동기 화 시간의 불연속 단절을 야기하고, 이로 인하여 시스 템 오류가 발생할 수 있다. 또한 RBS의 동기화 성능 은 무선채널에 의한 패킷 손실률과 밀접한 관계가 있 고, 특히 연속적인 패킷 손실로 인하여 동기화 성능이 크게 저하 될 수 있다.

본 논문에서는 RBS에서 발생할 수 있는 동기 화 시간의 불연속성으로 인한 문제점과 패킷 손실로 인한 성능 저하 문제점을 제시하고, 이러한 문제점을 해결하고자 연속 동기화 방식 (Continous Synchronization Mechanism)과 RBS의 패킷 손실 보 상 방법에 대하여 제안하고자 한다. 본 논문의 구성은 다음과 같다. 2장에서 클럭 동기화의 이론적 기초를 설명한다. 3장에서는 RBS 프로토콜을 소개하고, 시간 불연속성과 패킷 손실로 인한 성능 저하 문제점을 제 시한다. 4장에서는 RBS를 위한 연속 동기화 방식과 패킷 손실 보상 방법을 제안한다. 5장에서는 모의실험 결과에 대하여 분석하고, 6장에서 본 논문의 결론을 맺는다.

\section{II. 클럭 동기화 (Clock Synchronization)의 이론적 기초}

\section{1 수정 발진기의 표류 (Drift)}

수정 발진기는 공진 특성을 이용하여 특정 주파수 를 가진 전기적 신호를 발생시키는 전자 발진 회로이 다. 이러한 전기적 신호를 카운트하여 시간을 측정할 수 있다. 수정 발진기의 진동 주파수를 클럭 속도 (Clock Rate)라 한다. 시간을 정확하게 측정하기 위해 서는 클럭 속도가 항상 같은 값을 가져야 하지만 클럭 속도는 항상 가변이고, 클럭 속도의 변화를 클럭 표류 (Clock Drift)라 한다. 클럭 표류는 시스템적 표류 (Systematic Drift)와 확률적 표류 (Stochastic Drift)로 나뉜다.

시스템적 표류는 제조상의 편차와 환경적인 편차가 조합된 것이다. 수정 발진기의 제조 과정에서 생기는 오류로 인해 클럭은 모두 다른 편차를 가진다. 환경적 인 편차는 수정 발진기의 온도 변화 때문에 생기는 것 을 말한다. 시스템적 표류는 다음과 같이 정의 할 수 있다.

$$
p_{\text {syst }}=p_{\text {mann }}+R_{\text {syst }}(\text { temp }),
$$

$p_{s y s t}$ 는 시스템적 표류이고 $p_{m a n n}$ 는 제조과정의 오류로 생기는 편차이며 $R_{\text {syst }}$ (temp)는 온도로 인 해 생기는 편차를 나타낸다.

시스템적 표류와는 별개로 시간편차는 특정 구간에 서 불특정하게 변화하는데 이러한 편차를 확률적 표 류라고 한다. 측정한 결과에 따르면 확률적 표류는 온 도에 따라 변화하며 다음과 같이 공식화 할 수 있다.

$$
p_{\text {stoch }}=\operatorname{rand} \times\left(p_{\text {stoch, } \max }+R_{\text {stoch }}(\text { temp })\right),
$$

$p_{s t o c h}$ 는 확률적 표류, $r a n d$ 는 -1과 1사이의 무작위 숫자, $p_{s t o c h, \max }$ 는 확률적 표류의 상위범위이며 $R_{\text {stoch }}(t e m p)$ 는 온도로 인해 늘어난 표류 구간을 의 미한다.

이러한 시간 표류들로 인해서 분산 환경 시스템의 각 노드들은 다른 시간편차를 가지게 되고, 동기화 되 지 않은 클럭은 동기화가 필요하다. 시스템 내부의 $\mathrm{i}$ 번째 시간편차는 다음과 같이 공식화 할 수 있다.

$$
p^{i}=p_{\text {syst }}^{i}+p_{\text {syoch }}^{i} .
$$


앞서 언급한 바와 같이 시간표류는 시스템적 표류 와 확률적 표류의 조합이다. 마이크로 단위의 작은 시 간 주기를 측정하기 위해서 수백 $\mathrm{MHz} \sim \mathrm{GHz}$ 의 진동수 를 가진 수정 발진기가 초당 수백만 수천만번의 진동 을 발생시켜야 한다. 확률적 표류는 진동 주기에 계속 변화를 주게 된다. 그러나 수정 발진기가 수천만번의 진동을 일으키는 동안에 발생하는 확률적 표류는 통 계적으로 평균이 0 에 가깝기 때문에 무시될 수 있다. 다시 말해 확률적 표류는 마이크로 단위 혹은 그보다 긴 단위에서의 실험에서는 아무런 영향을 끼치지 못 한다. 그러므로 실제로의 문제는 시스템적 표류만 문 제가 된다.

그림 1은 섭씨 35 70도에서 5개 클럭의 시스템적 표류를 보여주고 있다. 그림을 보면 시간표류와 온도 의 관계가 선형이라고 할 수 없음을 분명히 알 수 있 다. 각각의 클럭은 온도에 상응하여 각자의 반응을 보 이고 있다. 수정 발진기 온도에 대한 반응은 제품과 버전이 같은 발진기라도 서로 상이하기 때문에 예측 할 수 없다. 하지만 다행히도 확률적 표류는 클럭 오 류에 아주 적은 영향을 주기 때문에, 클럭의 과거 동 작을 근거로 하여 현재 클럭에 대해서 적은 오차 범위 로 예측할 수 있다.

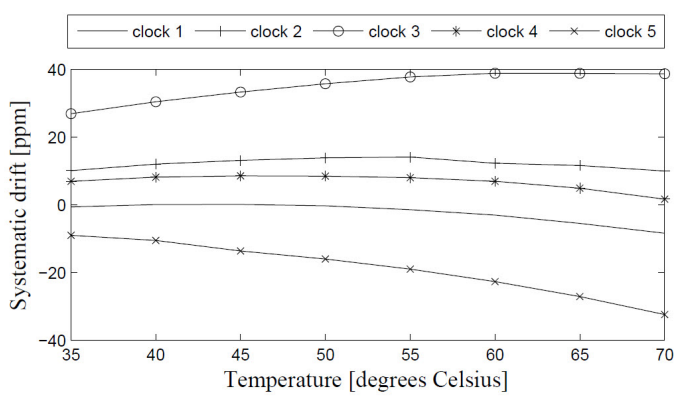

그림 1. 온도차에 따른 시간표류 변화

Fig. 1. Clock drift changing at different temperatures

\section{2 순간 클럭 동기화의 문제점}

클럭 동기화는 순간 클럭 동기화 (Instantanous Synchronization)와 연속 클럭 동기화 (Continous Synchronization)로 분류된다. 순간 클럭 동기화는 간 단한 방식으로 인하여 많이 사용되며, 대표적인 예가 $\mathrm{RBS}$ 이다. 연속 클럭 동기화는 구현 복잡도가 높아, 몇몇 동기화 프로토콜에 사용되어 진다 ${ }^{[4]}$.

순간 클럭 동기화는 시간 오프셋 계산 후 바로 로 컬 클럭에 적용한다. 이로 인하여 로컬 클럭의 순간적 인 변화를 초래하게 된다. [7]에서 지적된 바와 같이

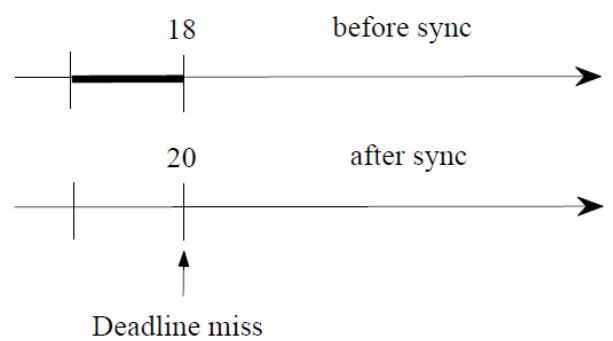

그림 2. 순간 조정에 의한 Deadline Miss

Fig. 2. Node missing deadline due to instantaneous correction

클럭의 순간적 역조정 (Backward Correction)으로 인 하여 시스템 불안정을 초래할 수 있다. 또한 그림 2에 서와 같이 클럭의 순간적 순조정 (Forward Correction)으로 인하여 시스템의 작업 마침 시간 (Deadline)을 놓칠 수 있다 ${ }^{[6]}$.

연속 동기화 방식은 순간적 조정이 아닌 주어진 기 간 동안 연속적인 단계적 클럭 조정을 통하여 순간 동 기화 방식의 단점을 보완한다.

\section{Reference Broadcast Synchronization (RBS)와 그 한계점}

\subsection{RBS 프로토콜}

$\mathrm{RBS}$ 에서 동기화 수행을 위해 특정 송신기는 모든 수신기들에게 기준 설정 패킷 (Reference Packet)을 브로드 캐스트한다. 각각의 수신기는 로컬 시간을 기 준으로 기준 설정 패킷이 수신되는 시간을 기록한다 (Timestamp). 기록된 시간은 주변 수신기들에게 브로 드캐스트로 전송하여 서로의 로컬 클럭을 조정하는데 사용하게 한다.

$\mathrm{RBS}$ 는 공통 브로드캐스트 채널 사용으로 인하여 클럭 오류의 주요인 중 전송 시간 및 채널 접근 시간 에서 발생하는 시간 편차를 제거하였다. 또한 전파 시 간으로 인한 오류는 전파속도가 빛의 속도에 근접하 고 비교적 짧은 거리를 전파하기 때문에 단지 몇 나노 단위의 오류를 발생시키기 때문에, 전파 시간으로 인 한 오류는 무시해도 된다. RBS에서 발생하는 클럭 오 류의 주요인은 수신 시간에서 발생하는 편차이다. [4] 에서 보인 바와 같이 비교적 짧은 기간 동안 수신시간 편차로 인해 발생하는 클럭 오류 분포는 가우시간 분 포인 $\mu=0, \sigma=11.1 \mu \mathrm{sec}$ 갖는다. 이러한 편차를 극 복하기 위해서 RBS는 일정 주기 동안 기준 설정 패킷 을 연속적으로 전송하고, 이들을 통한 오프셋 그룹을 계산 한 이후, Best-Fit 근사 방법으로 클럭을 보정한다. 


\subsection{RBS에서의 시간 불연속 문제}

전 장에서 기술 하였듯이, RBS에서 사용하는 순간 클럭 동기화 방식은 정조정 또는 역조정에 상관없이 시간 불연속 문제를 야기한다. 분산 환경의 각 노드들 은 클럭 동기화를 위하여 클럭 동기화 주기를 설정하 고, 각 주기 동안 기준 설정 패킷을 연속적으로 전송 하여 클럭의 오프셋을 계산하게 된다. 그림 3(a)에서 보인바와 같이 순간 클럭 동기화 방식을 사용할 경우 특정 노드에서 계산된 오프셋에 따라 각 주기 끝에 불 연속 점 (Breaking Point)들이 발생하게 된다. 이러한 오프셋에서의 불연속 점들은 클럭 동기화를 수행할 때 그림 3(b)에 보인 바와 같이 시간 보정 시 갑작스 런 시간 간격을 초래한다.

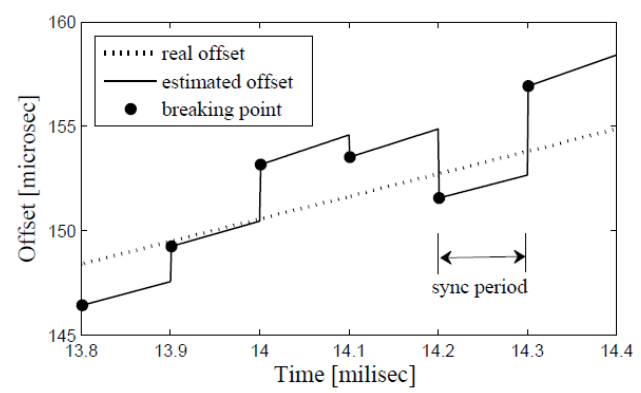

(a) Breaking point in estimated offset in RBS

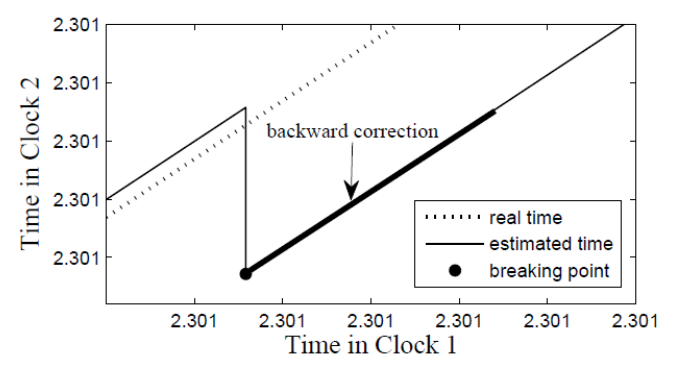

(b) Breaking point in estimated time in RBS

그림 3. RBS의 시간 불연속.

Fig. 3. Time discontinuity in RBS

\subsection{RBS의 성능에 대한 패킷 손실 영향}

수신시간 편차로 인한 클럭 표류 이외에, RBS 동 기화는 패킷 손실에 의해 영향을 받는다. 앞서 언급 한 바와 같이, RBS는 수신시간 편차를 보정하기 위하 여 주어진 동기화 주기동안 다수의 기준 설정 패킷 연 속적으로 전송한다. [4]에서 보인바와 같이 주어진 주 기 동안 더 많은 기준 설정 패킷을 전송함에 따라 클 럭 동기화 성능이 개선된다. 하지만 너무 과다한 전송 은 동기화 수렴시간을 길어지게 하는 단점이 있다.

그림 4 는 주어진 주기동안 30 개의 기준 설정 패킷
을 전송한 경우에 대하여 클럭 동기화 성능에 패킷 손 실이 미치는 영향의 예를 도시하고 있다. 그림에서와 같이 패킷 손실에 없을 경우의 Best-Fit 결과가 패킷 손실이 있는 경우의 Best-Fit 결과보다 실제 클럭 오 프셋과 가까운 것을 볼 수 있다.

$\mathrm{RBS}$ 의 성능 저하는 패킷 손실의 정도에 의존한다. [7-8]는 조밀한 센서 네트워크에서의 패킷 손실률이 $50 \%$ 까지 될 수 있다는 것을 보여 주었다. 또한 평균 패킷 손실률을 $0.1 \%$ 인 경우에도 순간 패킷 손실률은 $10 \%$ 보다 높은 패킷 손실률을 보일 수 있다. 더욱이 연속적인 패킷 손실이 발생하게 되면 RBS의 성능이 더욱 심각하게 저하 된다.

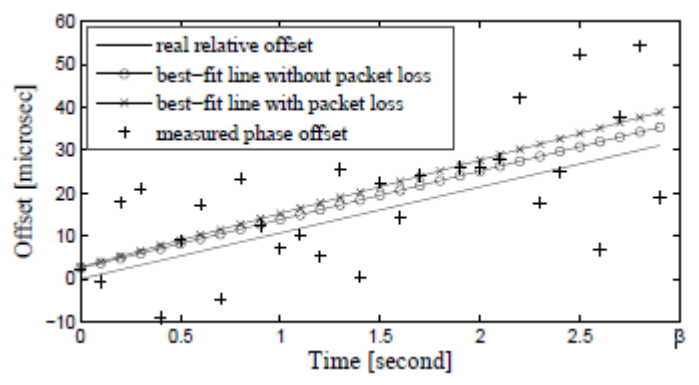

그림 4. RBS의 성능에 대한 패킷 손실의 영향

Fig. 4. Effect of packet loss on the performance of RBS

\section{RBS의 연속 클럭 동기화 및 패킷 손실 보상}

\subsection{RBS 연속 클럭 동기화}

[3]에서 제안된 프로토콜에서는 Rate-Based 알고리 즘을 사용하여 이웃 노드 클럭을 점차적으로 동기화 하였다. 이러한 개념을 적용하여 본 논문에서는 RBS 를 위한 연속 클럭 동기화를 제안한다. 제안하는 RBS 연속 클럭 동기화에서는 동기화 시작 시간에 불연속 점이 존재할 경우 이후에 기술되는 방식에 따라 점진 적으로 클럭을 보정한다.

그림 5(a)와 (b)는 RBS에서 불 연속점이 존재하는 역조정과 순조정의 예를 도시하고 있다. 두 경우에 있 어서 클럭 1 은 선형 맵핑 공식에 의해 클럭을 보정하 게 된다 $\left(C_{2}(t)=C_{1}(t)+o f f s e t(t)\right)$. 이때 그림 5(a) 와 (b)의 경우 불 연속점으로 인하여 보정시간에 순 간적인 시간 간격이 존재하게 된다.

이를 해결하기 위하여 선형 매핑 공식을 비선형 매 핑 공식으로 대치한다. 이때 사용되는 비선형 매핑 공 식은 Quadratic Bezier 곡선 $\mathrm{Q}(\mathrm{t})$ 로 다음과 같이 표현 된다. 


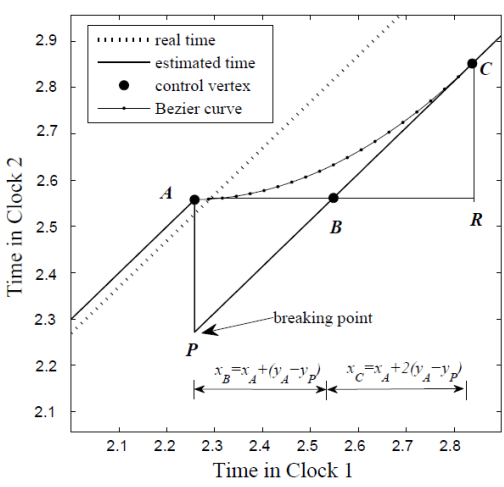

(a) Abrupt decreasing in the estimated time

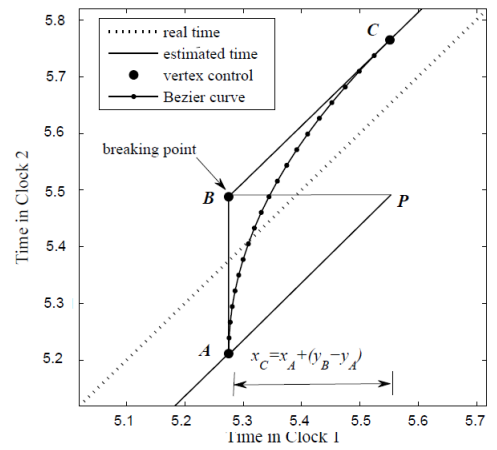

(b) Abrupt increasing in the estimated time

그림 5. RBS에 연속 동기화 기법 적용

Fig. 5. Apply continuous synchronization for RBS

$$
Q(t)=(1-t) A+2(1-t) t B+t^{2} C, t \in[0,1] .
$$

곡선 $\mathrm{Q}(\mathrm{t})$ 를 결정하기 위해서 필요한 것은 세 점 $\mathrm{A}, \mathrm{B}, \mathrm{C}$ 이다.

그림 5(a)의 역조정의 경우 주어진 $\mathrm{x}_{\mathrm{A}}$ 에 대하여 $\mathrm{x}_{\mathrm{B}}$ 는 $x_{B}=x_{A}+\left(y_{A}-y_{P}\right)$ 으로 구해진다. 이때 이등변 삼각형 $\mathrm{ABP}$ 의 변AP와 변AB가 같다는 성질을 이용 하였다. 또한 $\mathrm{x}_{C}$ 는 $x_{C}=x_{A}+2\left(y_{A}-y_{P}\right)$ 으로 구해진 다. 이때 두 이등변 삼각형 $\mathrm{ABP}, \mathrm{RBC}$ 에서 변 $\mathrm{AB}$ 와 변BR이 같다는 성질을 이용하였다. 그림 5(b) 순조정 의 경우 주어진 $\mathrm{x}_{\mathrm{A}} \quad\left(=\mathrm{x}_{\mathrm{B}}\right)$ 에 대해 $\mathrm{x}_{\mathrm{C}}$ 는 $x_{C}=x_{A}+\left(y_{B}-y_{A}\right)$ 으로 구해진다. 이때 이등변삼각 형 $\mathrm{BAP}$ 의 변AB와 변BP가 같다는 성실을 이용하였 다.

\subsection{RBS 패킷 손실 보상}

대부분의 클럭 동기화 방식은 다수의 기준 설정 패 킷을 전송함으로써 패킷 손실에 따른 성능 저하를 피 하고자 하였다 ${ }^{\{5,11\}}$. [5]에서는 패킷 손실을 보상하기
위하여 매 전송 마다 복수개의 정보를 전송하였다. 본 논문은 [5]에서 제안한 방식과 기본 개념을 같으나, 패킷 손실 보상 방법은 채널 상황을 고려하여 적응적 으로 복수개의 패킷을 전송한다는 측면에서 차이가 있다.

이를 자세히 살펴보면, RBS에서 모든 수신 노드는 기준 설정 패킷을 수신하면 해당 패킷의 도착 시간 (Timestamp)을 기록한다. 이후 각 수신 노드는 이웃 노드들에게 기록된 수신 시간을 브로드캐스트로 전송 하여 이를 수신한 노드들이 오프셋을 계산하여 클럭 을 보정하도록 한다. 하지만 특정 노드가 도착 시간을 전송하지만 패킷 손실이 발생하게 되면 이웃 노들들 은 오프셋을 계산하지 못하게 되어 클럭 보정에 문제 가 발생하게 된다.

BPLR을 버스트 패킷 손실 비율로 정의하자. 평균 BPLR에 비해 순간 BPLR은 10배 이상의 높은 손실 률을 가질 수 있다. $\mathrm{m}$ 을 오프셋 계산에 필요한 한 주 기동안 교환해야 하는 메시지 숫자로 정의하자. 제안 하는 패킷 손실 보상 방법은 버스트 패킷 손실률에 적 응적으로 $\mathrm{BPLR}{ }^{*} \mathrm{~m}+1$ 만큼의 과거 도착 기록을 전송 한다.

구체적으로 도착시간 브로드캐스트를 수신한 시간 을 $t_{i}$ 라고 가정하면, 노드는 자신의 도착시간을 메시 지 $m_{i}$ 에 포함시켜 다른 이웃 노드들과 서로 교환한 다. 그러면 패킷 손실률에 따라 메시지 $m_{i}$ 는 현재 도 착 시간인 $t_{i}$ 뿐만 아니라 과거 도착 시간들인 $t_{i-1}$, $t_{i-2}, \ldots, t_{i-B P L R^{*} m-1}$ 의 값을 포함하게된다.

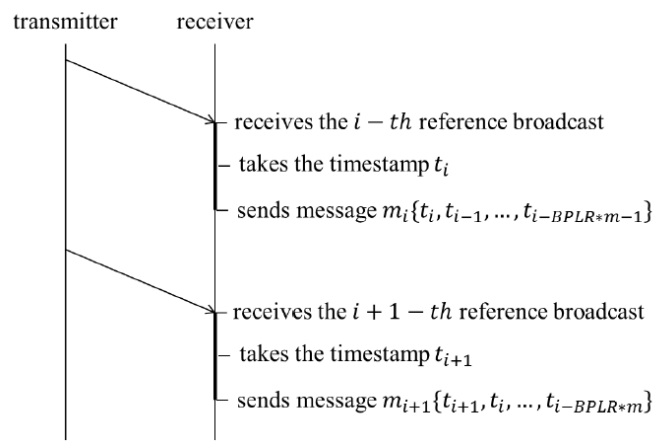

그림 6. RBS에 패킷 손실 보상 기법 적용

Fig. 6. Packet loss tolerance method

\section{V. 모의실험 분석}

본 논문에서는 5 개의 노드로 구성된 WSN을 30 분 동안 작동시켜 모의실험을 수행 하였다. 모의실험 시 
간동안 온도는 그림 7에서 같이 섭씨 35 70도로 변화 하도록 하였다. 각 클럭은 온도변화에 따라 다르게 반 응한다. 본 모의실험에서는 5 개의 클럭이 그림 1 에 따 라 변화한다고 가정하면 $\mathbf{5}$ 개 클럭의 시스템적 표류는 그림 8와 같고, 클럭의 상대적 오프셋은 그림 9와 같다.

앞서 언급 한 바와 같이, 전파 시간으로 인한 편차 를 0으로 간주하고, 수신 시간으로 인한 편차는 그림 10 과 같이 가우스 분포 $\mu=0, \sigma=11: 1 \mu \mathrm{sec}$ 를 갖 는 랜덤 변수로 간주된다. 평균 패킷 손실률은 30 분의 전체시간에 대해 $0.1 \%$ 로 가정한다. 그러나 순간 패 킷 손실률은 패킷 손실이 연속 손실로 발생하고 $10 \%$ 까지 패킷 손실이 발생하는 상황을 고려하였다.

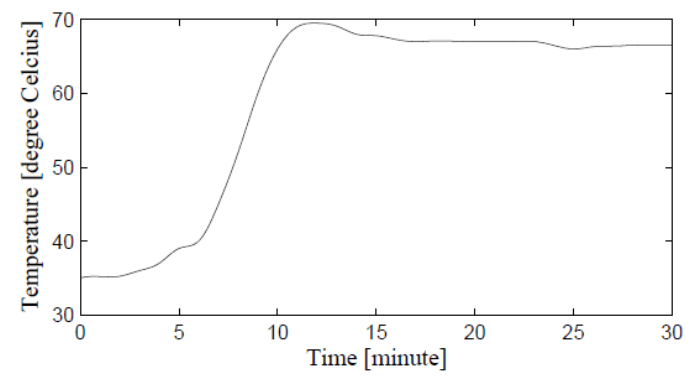

그림 7. 30 분 동안의 온도변화

Fig. 7. Changing of temperature during 30 minutes

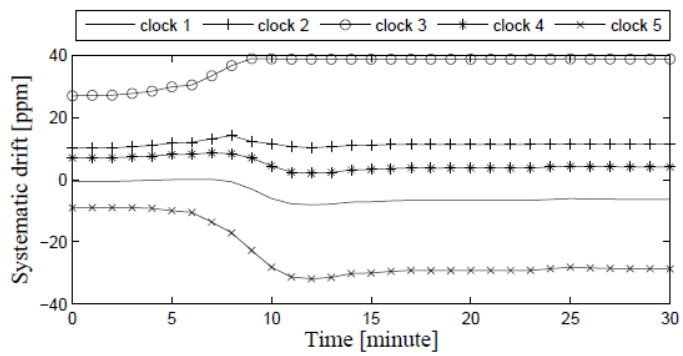

Fig. 8. Clock drifts during 30 minutes

그림 8. 30 분 동안의 클럭 표류

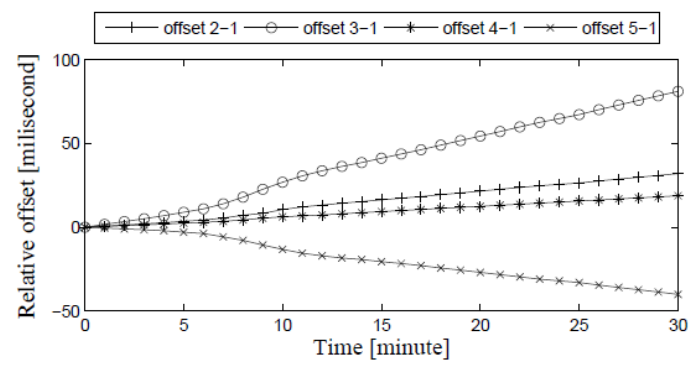

그림 9. 클럭 1에 대비한 상대적 오프셋

Fig. 9. Relative offsets compared to clock 1

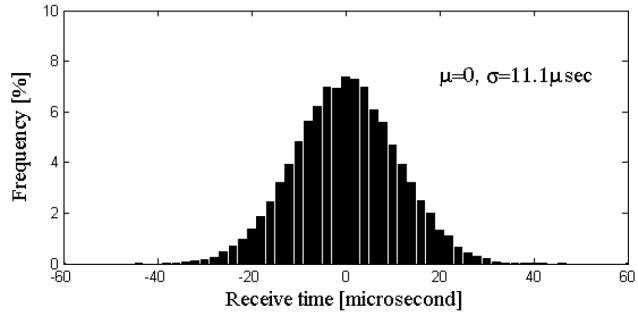

그림 10. 수신 시간의 분포

Fig. 10. Distribution of receive time

패킷 손실 보상에 따른 성능 차이를 보이고자 두 가지의 RBS 성능을 평가하였다 (RBS without packet tolerance, PBS with packet tolerance). 오프셋 예측에 필요한 교환해야하는 패킷 수는 4 개에서 40 개 까지 변화하며 성능을 측정하였다. 그림 11은 오프셋 예측 에 필요한 교환 패킷 수에 따른 두 RBS의 오프셋 예 측 오류에 대한 성능을 비교하고 있다. 두 RBS의 오 류 성능 차이는 교환 패킷 수가 증가 함에 따라 감소 함을 볼 수 있다. 즉 오프셋 예측에 필요한 패킷 수를 증가함에 따라 좀 더 정확한 예측이 가능함을 보인다. 하지만 교환 패킷 수의 증가는 오프셋 예측 시간의 수 렴 시간이 증가함을 의미한다. 교환 패킷 수가 15 이 하 인 경우 패킷 손실 보상을 하는 RBS가 패킷 손실 보상을 하지 않은 경우에 대비해 최대 오류 성능에서 우수함을 보인다. 두 RBS가 평균 오류에서는 비슷한 성능을 보이는데, 이는 $0.1 \%$ 의 낮은 패킷 손실 확률 과 순간적으로 높은 손실확률은 드물게 발생하고 평 균치에는 큰 영향을 주지 않음을 확인 할 수 있다.

그림 12 는 연속 클럭 동기화를 수행할 때 두 RBS 의 순간적으로 발생하는 시간 간격 (Time Gap)의 최 대치 성능을 보여주고 있다. 순간 클럭 동기화의 경우 그림 5에서와 같이 상당히 큰 시간 간격이 발생하지 만, 연속 클럭 동기화의 경우 비선형 맵핑을 통하여

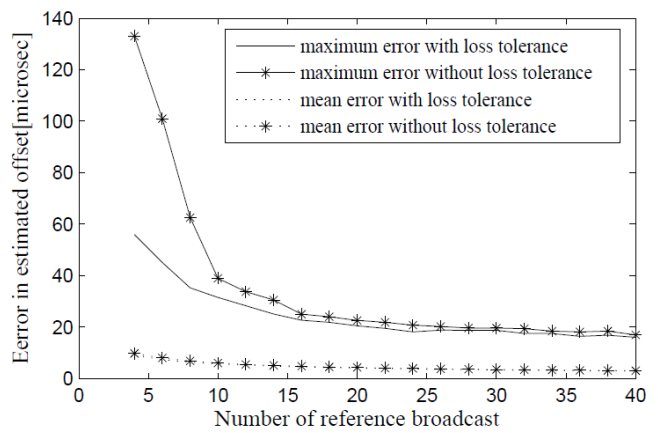

그림 11. 두 RBS 프로토콜의 오프셋 추정 오류

Fig. 11. Error of RBS with and without packet loss tolerance 


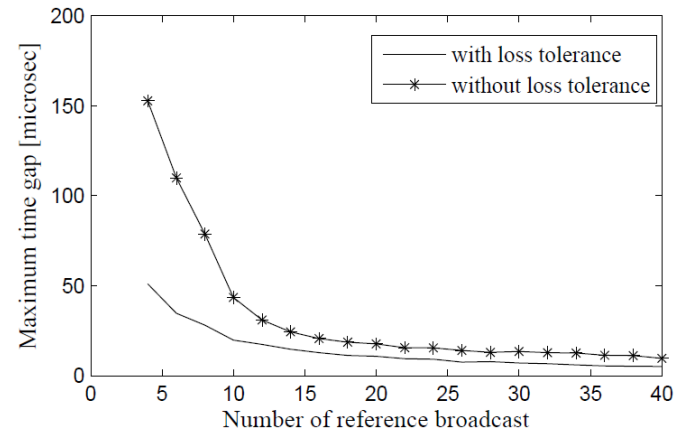

그림 12. 두 RBS 프로토콜의 연속 동기화 기법 적용시 최 대 오류 성능

Fig. 12. The maximum error performance of RBS with and without packet loss tolerance when continuous synchronization is applied

불연속 점을 제거하여 순간적으로 발생하는 시간 간 격을 상당히 감소 시켰다. 그러나 패킷 손실이 발생할 경우 오프셋 예측에 오류가 증가하게 된다. 오류가 증 가한다 함은 그림 5(a)의 경우 PBC 선이 실제 시간과 더욱 멀어져서 하향으로 계산되게 된다. 따라서 연속 클럭 동기화를 수행하게 되더라도 시간 간격은 증가 하게 된다. 그림 12 에서 와 같이 패킷 손실 보상을 하 는 RBS가 패킷 손실 보상을 하지않는 RBS에 비해 최대 시간 간격 성능이 우수함을 볼 수 있다.

\section{VI. 결 론}

RBS는 무선 센서 네트워크의 동기화를 위하여 가 장 널리 사용되는 프로토콜이다. 그러나 RBS에서 사 용되는 순간 클럭 동기화 방식은 순간적인 시간 조정 으로 인하여 시스템의 불안정을 초래할 수 있다. 또한 RBS는 패킷 손실 보상에 대한 기능을 전혀 고려하고 있지 않다. 본 논문에서는 RBS의 이러한 단점을 보완 하고자 RBS에 적용이 가능한 연속 클럭 동기화 방식 을 제안하였다. 또한 무선 채널을 통한 패킷 손실을 보상하고자 채널 환경에 적응적으로 대응 가능한 패 킷 손실 보상 방법을 제안하였다. 성능평가를 위하여 간략한 무선 센서 네트워크에 대한 모의실험을 수행 하였고 실험 결과에 따르면 제안한 연속 클럭 동기화 에 의하여 순간적으로 발생하는 시간 간격을 상당히 감소 시켰고, 또한 제안한 손실 패킷 보상 방식에 의해 $\mathrm{RBS}$ 의 오프셋 예측 성능을 향상 시킴을 확인하였다.

\section{References}

[1] T. Shon and K. Han, "Efficient mobile node authentication in WSN," J. KICS, vol. 35, pp. 833-839, May 2010.

[2] Y. I. Kim, B.-G. Choi, H. Lim, and M. Y. Chung, "Traffic_adaptive synchronized MAC protocol for wireless sensor networks," in Proc. KICS, pp. 861-862, Jun. 2009.

[3] U. Jeong and M. Kang, "Design of structures monitoring system using synchronized wireless sensor networks," in Proc. KICS, pp. 295-296, Nov. 2009.

[4] J. Elson, L. Girod, and D. Estrin, "Fine-grained network time synchronization using reference broadcasts," in Proc. OSDI, vol. 36, pp. 147-163, Boston, Massachusetts, Dec. 2002.

[5] M. Mock, R. Frings, E. Nett, and S. Trikaliotis, "Continuous clock synchronization in wireless real-time applications," in Proc. IEEE SRDS, pp. 125-132, Nurnberg, Oct. 2000.

[6] B. Sundararaman, U. Buy, and A. D. Kshemkalyani, "Clock synchronization for wireless sensor networks: a survey," J. $A d$ Hoc Networks (Elsevier), vol. 3, pp. 281-323, Mar. 2005.

[7] L. Lamport, "Time, clocks, and the ordering of events in a distributed system," Mag. Communications $A C M$, vol. 21, no. 7, pp. 558-565, Jul. 1978.

[8] M. Ryu and S. Hong, "Revisiting clock synchronization problems: static and dynamic constraint transformations for correct timing enforcement," Technical Report No. SNU-EETR-1998-3, Seoul National Univ., South Korea, Sept. 1998.

[9] J. Zhao and R. Govindan, "Understanding packet delivery performance in dense wireless sensor networks," in Proc. SenSys'03, LA, California, pp. 1-13, Nov. 2003.

[10] J. Shin, R. Umakishore, and M. Ammar, "On improving the reliability of packet delivery in dense wireless sensor networks," in Proc. 
ICCCN, pp. 718-723, Honolulu, HI, Aug. 2007.

[11] J. L. Welch and N. Lynch, "A new faulttolerant algorithm for clock synchronization," J. Information Computation, vol. 77, no. 1, pp. 1-36, Apr. 1988.

\section{트렁홉도 (Trong-Hop Do)}

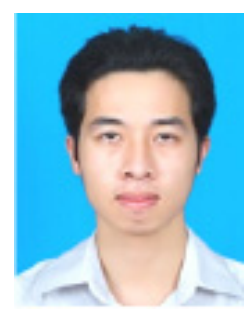

2009년 : University of Science

Ho Chi Minh City 학사 2009년 3월 현재 : 숭실대학교 정보통신전자공학부 석박통 합 과정

<관심분야> Optical Access

Network, Wireless MAC

Protocol, Visible Light

Communication, Social Network Services

박 근 원 (Kunwon Park)

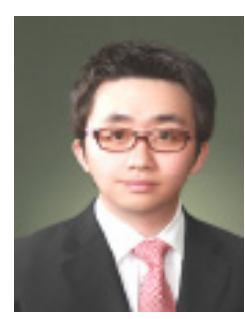

2013년 2월 : 숭실대학교, 정보 통신전자공학부 학사

2013년 3월 현재 : 숭실대학교

정보통신전자공학부석사과정

<관심분야> Visible Light

Communication
정 재 인 (Jaein Jung)

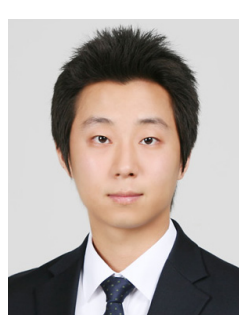

2014년 2월 : 숭실대학교 정보 통신전자공학부 학사

2014년. 3월 현재 : 숭실대학교 정보통신전자공학부석사과정 <관심분야> Social Network

Services

유 명 식 (Myungsik Yoo)

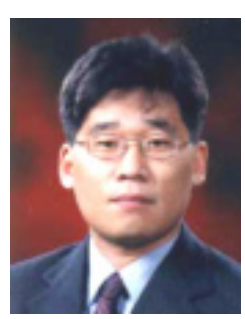

1989년 2월 : 고려대학교 전자 공학과학사

1991년 2월 : 고려대학교전자 공 학과 석사

2000년 6월 : SUNY at Buffalo

Dept. of EE 박사

2000년 9월 현재: 숭실대학교 정보통신전자공학부 교수

<관심분야> Optical Network, OBS, EPON, QoS, Wireless MAC Protocol, MANET, RFID/ USN, CR, Visible Light Communication 